\title{
ISOLAMENTO DE SALMONELLA spp E STAPHYLOCOCCUS qureUS EM CARNE DE FRANGO E CONDIÇÕES DOS ESTABELECIMENTOS COMERCIAIS NO MUNICÍPIO DE TUPÃ-SP
}

\author{
Erica Montezani, Rogério Giuffrida, Ricardo Augusto Pereira Andrade, Bruno Lima Silva
}

Universidade do Oeste Paulista - UNOESTE, Presidente Prudente, SP. E-mail : ericamontezani@gmail.com

\section{RESUMO}

O estudo propôs a avaliação das condições higiênico-sanitárias dos 55 estabelecimentos que comercializam carne de frango no município de Tupã-SP. Foram analisadas 70 amostras de carcaças e cortes de frango congelados e resfriados comercializados em supermercados e açougues. No momento da coleta, por meio de uma lista de verificação, foram abordadas questões referentes à identificação do estabelecimento, avaliação da rotulagem e armazenamento do produto seguido de uma análise microbiológica para avaliar a presença de Staphylococcus aureus e Salmonella spp nas amostras. O gênero $S$. aureus foi isolado em três amostras pesquisadas (4,2\%), com estimativas de contagens de $7,28 \times 10^{3}, 1,88 \times 10^{4}$ e $1,6 \times 10^{3} \mathrm{UFC} / \mathrm{g}$. Apenas uma amostra foi positiva para Salmonella spp (1,4\%). Apesar do baixo percentual de amostras contaminadas, a carne de frango comercializada no município oferece riscos à saúde dos consumidores em razão da conservação inadequada em temperaturas de armazenamento superiores às permitidas pela legislação.

Palavras-chave: toxinfecções, salmoneloses, aves, contaminação, saúde pública.

\section{ISOLATION OF SALMONELLA SPP AND STAPHYLOCOCCUS aureuS IN CHICKEN MEAT AND CONDITIONS IN COMMERCIAL ESTABLISHMENTS IN TUPA-SP CITY}

\begin{abstract}
This study proposed the evaluation of the hygienic and sanitary conditions of 55 outlets selling chicken in the city of Tupã-SP. We analyzed 70 samples of carcasses and cuts of frozen and chilled chicken sold in supermarkets and butcher shops. At the time of collection, through a checklist of questions, were raised regarding the identification of the establishment, evaluation and storage of the label product, after an microbial analyze for the presence of Staphylococcus aureus and Salmonella spp in samples. The genus $S$. aureus was isolated in three samples studied (4.2\%), with estimates of counts of $7.28 \times 10^{3}, 1.88 \times 10^{4}$ and $1.6 \times 10^{3} \mathrm{UFC} / g$. Just a sample was positive for Salmonella spp (1.4\%). Despite the low percentage of samples contaminated chicken meat sold in the city offers consumer health risks because of incorrect conservation temperatures in the upper storage allowed by law.
\end{abstract}

Keywords: toxinfections, salmonellosis, chickens, contaminations, public health.

\section{INTRODUÇÃO}

As condições sanitárias da comercialização da carne de frango devem estar sempre condizentes com padrões adequados de higiene exigidos pelas normas sanitárias, a fim de garantir a inocuidade dos produtos, proteger a saúde dos consumidores e reduzir prejuízos econômicos decorrentes da deterioração do produto $^{1,2}$.

A carne de frango pode ser contaminada por micro-organismos bacterianos durante diversas etapas da cadeia de produção onde as condições higiênicas e de conservação sejam deficitárias. A carga microbiana pode ser introduzida nos cortes e carcaças a partir de equipamentos, utensílios e ambiente em condições insatisfatórias de higiene, durante as etapas de abate, armazenamento, transporte e manipulação ${ }^{3}$.

Salmonella spp e Staphylococcus aureus (S. aureus) figuram como os agentes microbianos mais comuns em surtos de toxi-infecção no Brasil. Estes agentes foram os mais prevalentes em surtos notificados entre os anos de 1999 e 2004, quando foram registrados 3.737 surtos de doenças transmitidas por alimentos, com o 
acometimento de 73.517 indivíduos e registro de 38 óbitos $^{4}$.

Salmonella spp está presente no sistema digestório das aves e facilmente coloniza as carcaças de frango durante as etapas de abate ${ }^{5}$, enquanto $S$. aureus pode contaminar os cortes e carcaças a partir da pele e das vias respiratórias de manipuladores de alimentos e dos frangos vivos $^{6}$. Caso a carne seja mantida em condições insatisfatórias de conservação, a carga microbiana inicial de $S$. aureus é capaz de proliferar-se e produzir toxinas termoestáveis responsáveis por surtos de toxi-infecção em seres humanos ${ }^{7}$.

O presente estudo teve como objetivo avaliar as condições higiênico-sanitárias de estabelecimentos de vendas de carne de frango do comercio varejista do município de Tupã, SP e determinar a presença de $S$. aureus e Salmonella spp nestes produtos.

\section{METODOLOGIA}

As coletas foram realizadas durante 0 período de setembro de 2011 a janeiro de 2012 . Todos os produtos recolhidos foram mantidos em suas embalagens originais, armazenados em caixa térmica sob refrigeração/congelamento e transportados imediatamente ao laboratório onde as análises microbiológicas foram realizadas imediatamente após a coleta.

Foram avaliadas 70 amostras, sendo 31 carcaças e 39 cortes de frango, de 55 estabelecimentos comerciais relacionados na Figura 1, sendo 39 supermercados e 16 açougues. Das amostras recolhidas, 17 eram resfriadas e 53 congeladas, comercializados nas embalagens plásticas originais, sendo 54 em embalagens a vácuo e $16 \mathrm{em}$ bandejas de poliamida. As amostras foram recolhidas pela Vigilância Sanitária do Município de Tupã-SP.

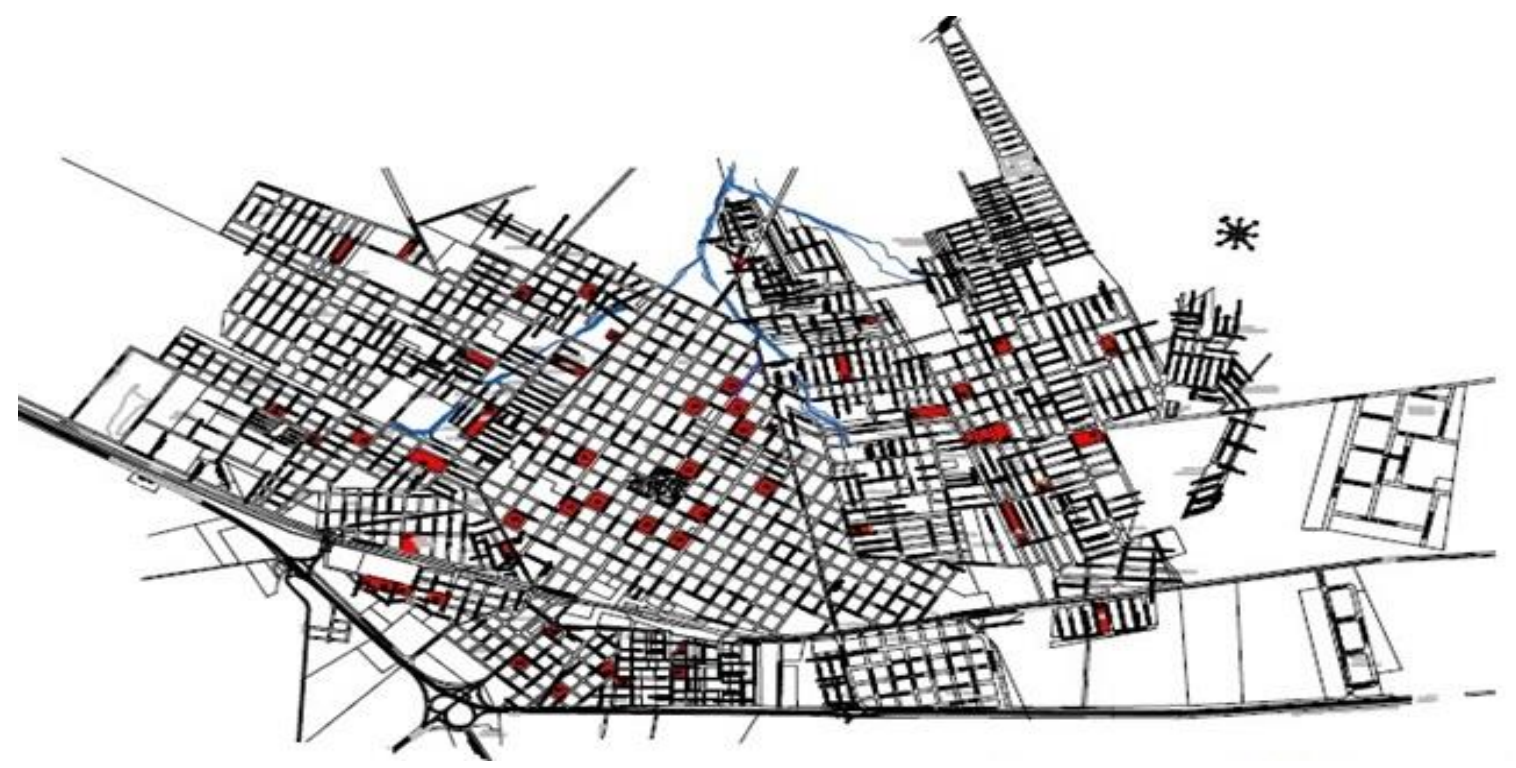

Figura 1. Indicação (pontos vermelhos) dos estabelecimentos de coleta.

Uma lista de verificação relacionada com a adoção de boas práticas de fabricação em estabelecimentos produtores/processadores de alimentos conforme recomendado em Portaria e Regulamento técnico específico da Agência Nacional de Vigilância Sanitária, RDC $n^{\circ} 275$ de 21 de outubro de $2002^{8}$ foi adaptada pela Vigilância Sanitária do município e aplicada aos estabelecimentos pesquisados a fim de verificar possíveis falhas no armazenamento dos produtos. As questões foram separadas em três partes: parte $A$, identificação, parte $B$, avaliação da rotulagem e armazenamento do produto e parte $\mathrm{C}$, contendo dados como tipo do produto, data, horário, marca e temperatura do freezer no momento da coleta. As opções de respostas para o preenchimento da lista foram "Conforme" (C) quando o estabelecimento atendeu ao item observado, "Não Conforme" (NC) - quando o mesmo apresentou não-conformidade. As avaliações foram realizadas pelos agentes fiscais do município na presença do responsável pelo estabelecimento.

Técnicas recomendadas pelo Ministério da Agricultura Pecuária e Abastecimento foram utilizadas para a análise de Salmonella spp e Staphylococcus aureus ${ }^{9}$.

Para o isolamento de Salmonella spp foram retirados, de cada embalagem, $25 \mathrm{~g}$ de cada amostra para semeadura em $225 \mathrm{~mL}$ de 
água peptonada tamponada. Após $12-24 \mathrm{~h}$ de incubação a $37^{\circ} \mathrm{C}, 1 \mathrm{~mL}$ do caldo resultante foi transferido em duplicata para tubos contendo 10 $\mathrm{mL}$ de caldo tetrationato de sódio de Kauffman e $0,1 \mathrm{~mL}$ para $10 \mathrm{~mL}$ de caldo RappaportVassiliadis. Após $12-24 \mathrm{~h}$ de incubação à $37^{\circ} \mathrm{C}$, uma alíquota de cada tubo foi semeada em ágar XLD (Xilose-Lisina-Deoxicolato) e ágar SalmonellaShigella. Após incubação a $37^{\circ} \mathrm{C}$ por 24 horas, as colônias isoladas e típicas de Salmonella, foram submetidas aos testes de produção de indol, produção das enzimas fenilalanina-desaminase, lisina descarboxilase e urease, utilização de carbono como fonte de energia, acidificação da lactose, glicose e sacarose, motilidade e produção de $\mathrm{H}_{2} \mathrm{~S}$. As colônias classificadas como Salmonella foram submetidas a testes de sorodiagnóstico com antisoro polivalente comercial (Probac $\left.{ }^{\circledR}\right)$.

Para isolamento do $S$. aureus, $25 \mathrm{~g}$ de cada amostra foram semeados em $225 \mathrm{~mL}$ de água peptonada tamponada para perfazer a diluição $10^{-1}$. A partir desta fração foram realizadas diluições seriadas na proporção de $10^{-2}$ e $10^{-3}$. De cada diluição retirou-se $0,1 \mathrm{~mL}$ de inóculo para semeadura superficial em duplicata em placas de Petri contendo Agar Baird-Parker suplementado com gema de ovo e telurito de potássio. Após incubação a $37^{\circ} \mathrm{C}$ por $24-48 \mathrm{~h}$, as colônias bacterianas fenotipicamente compatíveis com $S$. aureus foram enumeradas e identificadas por meio dos testes de avaliação morfotintorial pelo método de Gram, produção de catalase, fermentação do manitol em meio com alta concentração de sal, produção de plasma-coagulase e produção de DNAase. As contagens bacterianas foram expressas em Unidades Formadoras de Colônias por $\mathrm{mL}$ de amostra (UFC/mL). A fim de determinar se as linhagens de $S$. aureus isoladas apresentavam o fenótipo de resistência a meticilina, os isolados foram submetidos ao teste de disco-difusão empregando-se o antimicrobiano oxacilina. A partir das colônias isoladas, foram preparados inóculos correspondentes à escala 0,5 de Mac Farlland para semeadura em Agar MüellerHinton, seguidas da adição de discos de papel impregnados com a oxacilina ${ }^{10}$. Após $24 \mathrm{~h}$ de incubação a $37^{\circ} \mathrm{C}$, os diâmetros das zonas de inibição foram mensurados e interpretados de acordo com os padrões internacionalmente aceitos do Clinical and Laboratory Standards Institute $e^{11}$.
Os resultados referentes à conformidade dos itens avaliados foram expressos em tabelas de frequências.

\section{RESULTADOS}

Apenas uma amostra de corte resfriado $(1,4 \%)$ foi positiva para Salmonella spp em $25 \mathrm{~g}$ de carne de frango. No município de Bauru-SP, foi observada a presença de seis amostras positivas para Salmonella em 102 amostras resfriadas ${ }^{12}$, entretanto, no município de Ponta Grossa-PR, foi verificada a ausência de amostras positivas para este agente em 50 amostras de frango resfriadas ${ }^{13}$.

Apesar do baixo percentual observado nesta pesquisa, alguns estudos sugerem que o agente pode estar presente em um maior número de amostras de carcaças de frangos, variando de $0,24 \%$ a $85 \%{ }^{14}$.

$\mathrm{O}$ isolamento deste agente ocorreu a partir de um corte resfriado. Considera-se atualmente, que a presença deste agente na carne de aves e seus miúdos crus, resfriados ou congelados, é um problema mundial e que não existem medidas efetivas de controle que possam eliminar esta bactéria da carne crua. Desta forma, uma medida racional para evitar a ocorrência de surtos é a educação sanitária da população, objetivo que tenta ser alcançado com a RDC $n^{\circ} 13$ de 2 de janeiro de 2001 da Agência Nacional da Vigilância Sanitária (ANVISA) que exige as orientações na rotulagem do produto sobre o uso, o preparo e a conservação adequada do mesmo, a fim de auxiliar o consumidor no controle do risco associado ao consumo de alimentos contaminados ${ }^{15}$.

Staphylococcus spp foi detectado em dez amostras $(14,2 \%)$, no entanto, os testes bioquímicos permitiram observar somente três linhagens $(4,2 \%)$ caracterizadas como coagulasepositivas, com contagens estimadas em $7,28 \times 10^{3}$, $1,88 \times 10^{4}$ e $1,6 \times 10^{3} \mathrm{UFC} / \mathrm{g}$. Todos os isolamentos foram provenientes de cortes resfriados, assim como o isolamento de Salmonella spp. Em estudo realizado em 20 amostras de carne de frango coletadas em Recife-PE foram observadas sete amostras positivas para $S$. aureus, com contagens bacterianas variando de $10^{1}$ a $10^{2} \mathrm{UFC} / \mathrm{g}^{16}$. Resultados divergentes foram encontrados ao analisar 20 carcaças de frango comercializadas no município de Seropédica-RJ, não sendo observada a presença de $S$. aureus nas amostras analisadas $^{17}$, enquanto no município de Ponta Grossa-PR, foram observadas 50 amostras de 
frango resfriadas e detectada a presença de $S$. aureus em 20 delas, com contagens variando entre $1,1 \times 10^{1}$ e $4,7 \times 10^{1} \mathrm{UFC} / \mathrm{g}^{13}$.

Apesar de a Resolução RDC $n^{\circ} 12$, de 2 de janeiro de 2001 da ANVISA, que aborda os padrões microbiológicos para a contagem de Staphylococcus coagulase-positiva em carne in natura não estabelecer critérios específicos para a carne de frango, os resultados observados indicam que $\mathrm{o}$ agente isolado apresenta contagens superiores a $1 \times 10^{3} \mathrm{UFC} / \mathrm{g}$, limite considerado seguro para carne e produtos cárneos de forma geral ${ }^{18}$. Por outro lado, amostras que apresentam contagem de Staphylococcus spp abaixo de $5 \times 10^{3} \mathrm{UFC} / \mathrm{g}$ são consideradas aceitáveis para o consumo, e neste caso, apenas uma das amostras seria considerada inadequada $^{19}$.

Conforme diagnósticos da lista de verificação de condições higiênico-sanitárias dos estabelecimentos foram verificados não conformidades em alguns itens relacionados à rotulagem e armazenamento dos produtos conforme apresentados na Tabela 1.

Tabela 1. Itens em conformidade (C) e não-conformidade (NC) verificada nos estabelecimentos em relação à rotulagem e armazenamento dos produtos.

\begin{tabular}{|c|c|c|c|c|c|c|}
\hline \multirow{2}{*}{ Itens Avaliados } & \multicolumn{2}{|c|}{ Supermercados } & \multicolumn{2}{|c|}{ Açougues } & \multicolumn{2}{|c|}{ Total } \\
\hline & $C$ & NC & $C$ & $\mathrm{NC}$ & $C$ & NC \\
\hline $\begin{array}{l}\text { a. Número do lote e data de fabricação } \\
\text { do produto impressos adequadamente } \\
\text { na embalagem }\end{array}$ & $\begin{array}{r}39 / 39 \\
(100 \%)\end{array}$ & $\begin{array}{l}0 / 39 \\
(0 \%)\end{array}$ & $\begin{array}{l}16 / 16 \\
(100 \%)\end{array}$ & $\begin{array}{l}0 / 16 \\
(0 \%)\end{array}$ & $\begin{array}{l}55 / 55 \\
(100 \%)\end{array}$ & $\begin{array}{l}0 / 55 \\
(0 \%)\end{array}$ \\
\hline $\begin{array}{l}\text { b. Validade dos produtos dentro do } \\
\text { prazo correto }\end{array}$ & $\begin{array}{l}39 / 39 \\
(100 \%)\end{array}$ & $\begin{array}{l}0 / 39 \\
(0 \%)\end{array}$ & $\begin{array}{l}16 / 16 \\
(100 \%)\end{array}$ & $\begin{array}{l}0 / 16 \\
(0 \%)\end{array}$ & $\begin{array}{l}55 / 55 \\
(100 \%)\end{array}$ & $\begin{array}{l}0 / 55 \\
(0 \%)\end{array}$ \\
\hline $\begin{array}{l}\text { c. Produto acondicionado em } \\
\text { embalagens adequadas e íntegras } \\
\text { d. Dizeres de rotulagem de acordo com a }\end{array}$ & $\begin{array}{l}39 / 39 \\
(100 \%)\end{array}$ & $\begin{array}{l}0 / 39 \\
(0 \%)\end{array}$ & $\begin{array}{l}16 / 16 \\
(100 \%)\end{array}$ & $\begin{array}{l}0 / 16 \\
(0 \%)\end{array}$ & $\begin{array}{l}55 / 55 \\
(100 \%)\end{array}$ & $\begin{array}{l}0 / 55 \\
(0 \%)\end{array}$ \\
\hline $\begin{array}{l}\text { legislação vigente em relação ao uso, o } \\
\text { preparo e a conservação adequada dos } \\
\text { produtos }\end{array}$ & $\begin{array}{l}39 / 39 \\
(100 \%)\end{array}$ & $\begin{array}{l}0 / 39 \\
(0 \%)\end{array}$ & $\begin{array}{l}16 / 16 \\
(100 \%)\end{array}$ & $\begin{array}{l}0 / 16 \\
(0 \%)\end{array}$ & $\begin{array}{l}55 / 55 \\
(100 \%)\end{array}$ & $\begin{array}{l}0 / 55 \\
(0 \%)\end{array}$ \\
\hline $\begin{array}{l}\text { e. Produtos armazenados separados por } \\
\text { grupos }\end{array}$ & $\begin{array}{c}35 / 39 \\
(89,7 \%)\end{array}$ & $\begin{array}{c}4 / 39 \\
(10,3 \%)\end{array}$ & $\begin{array}{l}15 / 16 \\
(93,7 \%)\end{array}$ & $\begin{array}{l}1 / 16 \\
(6,3 \%)\end{array}$ & $\begin{array}{l}50 / 55 \\
(90,9 \%)\end{array}$ & $\begin{array}{c}5 / 55 \\
(9,1 \%)\end{array}$ \\
\hline $\begin{array}{l}\text { f. Armazenamento adequado dentro da } \\
\text { linha de segurança do freezer }\end{array}$ & $\begin{array}{c}35 / 39 \\
(89,7 \%)\end{array}$ & $\begin{array}{c}4 / 39 \\
(10,3 \%)\end{array}$ & $\begin{array}{l}15 / 16 \\
(93,7 \%)\end{array}$ & $\begin{array}{l}1 / 16 \\
(6,3 \%)\end{array}$ & $\begin{array}{l}50 / 55 \\
(90,9 \%)\end{array}$ & $\begin{array}{c}5 / 55 \\
(9,1 \%)\end{array}$ \\
\hline $\begin{array}{l}\text { g. Características organolépticas } \\
\text { normais: produtos com cor, odor, } \\
\text { consistência e aspectos sem alteração }\end{array}$ & $\begin{array}{l}39 / 39 \\
(100 \%)\end{array}$ & $\begin{array}{l}0 / 39 \\
(0 \%)\end{array}$ & $\begin{array}{l}15 / 16 \\
(93,7 \%)\end{array}$ & $\begin{array}{l}1 / 16 \\
(6,3 \%)\end{array}$ & $\begin{array}{l}54 / 55 \\
(98,1 \%)\end{array}$ & $\begin{array}{c}1 / 55 \\
(1,9 \%)\end{array}$ \\
\hline $\begin{array}{l}\text { h. Local de armazenamento dos } \\
\text { produtos em boas condições de higiene }\end{array}$ & $\begin{array}{l}35 / 39 \\
(92,8 \%)\end{array}$ & $\begin{array}{c}4 / 39 \\
(7,2 \%)\end{array}$ & $\begin{array}{l}12 / 16 \\
(75,0 \%)\end{array}$ & $\begin{array}{c}4 / 16 \\
(25,0 \%)\end{array}$ & $\begin{array}{l}47 / 55 \\
(85,5 \%)\end{array}$ & $\begin{array}{c}8 / 55 \\
(14,5 \%)\end{array}$ \\
\hline $\begin{array}{l}\text { i. Produtos com prazo de validade } \\
\text { vencido e recolhidos do mercado } \\
\text { devidamente identificados e } \\
\text { armazenados em local separado e de } \\
\text { forma organizada }\end{array}$ & $\begin{array}{l}39 / 39 \\
(100 \%)\end{array}$ & $\begin{array}{l}0 / 39 \\
(0 \%)\end{array}$ & $\begin{array}{l}16 / 16 \\
(100 \%)\end{array}$ & $\begin{array}{l}0 / 16 \\
(0 \%)\end{array}$ & $\begin{array}{l}55 / 55 \\
(100 \%)\end{array}$ & $\begin{array}{l}0 / 55 \\
(0 \%)\end{array}$ \\
\hline
\end{tabular}

\section{DISCUSSÃO}

Problemas de higiene, mais especificamente, relacionados à limpeza dos freezers de armazenamento da carne de frango foram verificados em oito dos 55 estabelecimentos comerciais $(14,5 \%)$, sendo quatro de 16 (25\%) açougues e quatro de 39 supermercados (7,2\%). Estas observações concordam com pesquisa realizada em Uberaba$M G$, onde foi constatada que a higienização dos freezers de armazenamento de carnes em açougues e supermercados estava fora da conformidade $^{20}$. As amostras positivas para os patógenos pesquisados no presente trabalho 
foram, na sua totalidade, oriundas dos estabelecimentos considerados como em nãoconformidade com relação a este item. No entanto, os micro-organismos isolados da carne pesquisada, provavelmente não foram oriundos de materiais presentes nas gôndolas, visto que a carne de frango avaliada estava em embalagens originais. Apesar disso, os cortes contaminados podem representar perigos para os outros produtos armazenados conjuntamente, pois a maior parte das sujidades observadas pode ser decorrente de vazamentos dos conteúdos das embalagens.

Em relação ao item que aborda a armazenagem dos produtos separados por grupos, cinco dos 55 estabelecimentos (9\%) foram considerados como irregulares, sendo quatro de 39 supermercados $(10,3 \%)$ e um de 16 açougues (6,3\%). Esta prática pode ocasionar a contaminação cruzada entre produtos ${ }^{21}$. Já com relação ao armazenamento adequado dentro da linha de segurança, foi observado que quatro de 39 supermercados $(10,3 \%)$ e um de 16 açougues (6,3\%) estavam em não conformidade. Esta é uma prática comum adotada por entrepostos de venda de carne para e exposição de produtos e pode acarretar dificuldade na circulação de ar frio dentro do freezer, o que compromete a conservação dos alimentos ${ }^{22}$.

Apenas em um dos 55 estabelecimentos, no caso, um dos açougues pesquisados, foi observada a presença de produtos com as características organolépticas anormais. As alterações nestas características, além de indicarem processos de deterioração do produto, podem acarretar a rejeição no momento da compra, pois a qualidade do produto é um item essencial para os consumidores ${ }^{23}$. Os demais itens abordados na lista de verificação estavam em plena conformidade.

Interessantemente, os percentuais de positividade para ambos os micro-organismos ocorreram em apenas uma das 13 marcas comerciais pesquisadas $(7,6 \%)$ o que pode indicar falhas nos sistemas de biossegurança adotados pela empresa produtora durante $\mathrm{o}$ abate dos frangos.

Todas as amostras positivas para os agentes pesquisados foram oriundas de cortes refrigerados. Considerando-se que nos abatedouros, a separação em cortes pode ser realizada manualmente pelos trabalhadores das empresas, os agentes isolados, em especial, $S$. aureus, podem ter contaminado a carne após o contato durante a manipulação, visto que, indivíduos doentes ou portadores assintomáticos de micro-organismos patogênicos são fontes contumazes de contaminação para estes produtos ${ }^{24}$. Após a contaminação, deficiências das condições de armazenamento ou conservação da carne propiciam a proliferação de $S$. aureus e consequente contaminação dos produtos com as enterotoxinas, sendo a educação sanitária dos manipuladores uma ferramenta fundamental para assegurar a qualidade dos alimentos e a saúde do consumidor.

Em todos os estabelecimentos pesquisados, não foi observado o fracionamento de carcaças em cortes para venda a granel. Todas as amostras positivas foram oriundas de cortes de frango expostos à venda em bandejas de poliamida e/ou polietileno comercializadas por supermercados da região central do município. Esse material plástico apresenta variados graus de permeabilidade ao oxigênio, podendo favorecer o crescimento de microrganismos na carne de frango ${ }^{25}$.

Foi observado que apenas três das 53 $(5,6 \%)$ amostras congeladas avaliadas estavam na temperatura recomendada, o que pode propiciar a proliferação de agentes microbianos e incorrer em riscos de saúde pública. De acordo com a legislação sanitária vigente, portaria CVS $n^{\circ} 6$, de 10 de março de 1999, a temperatura de armazenagem de produtos cárneos congelados não deve ser superior a $-18^{\circ} \mathrm{C}^{26}$.

No momento da coleta, a temperatura média registrada para as amostras de carcaças e cortes congelados foi de $-11,8 \pm 3,8^{\circ} \mathrm{C}$ e para os resfriados foi de $4,1 \pm 0,99^{\circ} \mathrm{C}$, conforme registros do serviço de Vigilância Sanitária Municipal, realizados por meio do termômetro de superfície (digital portátil - Raytec ${ }^{\circ}$ ). Este parece ser um problema dominante nos estabelecimentos de venda de produtos alimentícios, e que pode ocorrer, entre outros fatores por quedas de energia nos períodos de pico e pela prática de desligamento $\mathrm{da}$ energia por parte dos estabelecimentos ${ }^{27}$.

Com relação aos cortes e carcaças refrigeradas, observou-se que seis de 17 (35,3\%) amostras pesquisadas, no momento da coleta encontrava-se em temperatura superior à recomendada pela legislação sanitária, o que reitera a possibilidade de patógenos bacterianos se multiplicarem no interior das embalagens expostas à venda. Ressalta-se que em alguns dos estabelecimentos avaliados, os termômetros estavam danificados, o que dificulta por parte dos próprios comerciantes e da população, o controle 
e a manutenção da temperatura ideal. Ao conservar a qualidade da carne é indispensável manter constante a temperatura de armazenamento de $3^{\circ} \mathrm{C}$ ou menos ${ }^{28}$, e, frangos resfriados e armazenados a $4^{\circ} \mathrm{C}( \pm 1)$ podem ter seu período de vida de prateleira diminuído ${ }^{29}$. A carne de frango normalmente é consumida após tratamento térmico e os riscos de infecção são reduzidos. No entanto, a presença da Salmonella spp e do $S$. aureus no alimento podem promover marcante deterioração ao produto além de produzirem toxinas termoresistentes ${ }^{6}$.

As amostras de $S$. aureus isoladas foram consideradas sensíveis à oxacilina. A resistência a este antimicrobiano é um indicador importante da expressão do fenótipo de multiresistência por linhagens de $S$. aureus, que podem estar presentes em produtos de origem animal ${ }^{30}$. Os resultados indicam que a carne de frango comercializada na região oferece baixo risco de veicular linhagens de $S$. aureus resistentes à meticilina para os consumidores, apesar do pequeno número de amostras bacterianas avaliadas.

Os resultados obtidos permitiram concluir que a carne de frango comercializada no município, apesar de apresentar percentuais baixos de contaminação por Salmonella spp e $S$. aureus, oferece riscos a saúde dos consumidores em razão da conservação inadequada em temperaturas de armazenamento superiores às permitidas pela legislação.

\section{AGRADECIMENTOS}

A Secretaria Municipal de Vigilância Sanitária do município de Tupã por todo o suporte necessário para a coleta das amostras. A PróReitoria de Pesquisa e Pós-Graduação da Universidade do Oeste Paulista pelo apoio financeiro.

\section{CONFLITO DE INTERESSE}

Os autores declaram não haver qualquer potencial conflito de interesse que possa interferir na imparcialidade deste trabalho cientifico.

\section{REFERÊNCIAS}

1. Fritzen AL, Sdiwerz DL, Gabiatti EC, Padilha V, Macari S. Análise microbiológica de carne moída de açougues pertencentes a regional de saúde do Paraná. Rev Higiene Alimentar. 2006;144(20):81-3 2. Coutinho EP, Oliveira AT, Francisco MS, Silva MJ, Silva JMS, Azeredo LPM. Avaliação das condições higiênico-sanitárias da manipulação e comercialização de carnes vermelhas e aves nas feiras livres dos municípios de Bananeiras e Solânea, PB. II Jornada Nacional de Agroindústria. Bananeiras-PB. 2007.

3. Zandonadi RP, Botelho RBA, Oliveira KES, Akutsu RCCA, Araújo WMC. Atitudes de risco do consumidor em restaurantes de auto-serviço. Rev Nutr. 2007;1(20):19-26.

DOI:

https://doi.org/10.1590/S1415-

\section{2}

4. Agência Nacional de Vigilância Sanitária ANVISA. Vigilância epidemiológica das doenças transmitidas por alimentos no Brasil. 1999-2004. Bol Eletr Epidemiol. 2005;5(6):1-7.

5. Newell DG, Koopmans M, Verhoef L, Duizer $E_{,}$ Kane $A A$, Sprong $\mathrm{H}$ et al. Food-borne diseases The challenges of 20 years ago still persist while new ones continue to emerge. Int J Food Microbiol. 2010;139(30):3-15. DOI: https://doi.org/10.1016/j.ijfoodmicro.2010.01.02 $\underline{1}$

6. Pardi MC, Santos IF, Souza ER, Pardi HS. Pardi MC, Santos IF, Souza ER, Pardi HS. Aspectos higiênico-sanitários da carne. Zoonoses mais comuns adquiridas profissionalmente por manipuladores de carne. In: Ciência, higiene e tecnologia da carne, 2.ed. Goiânia: CEGRAF-UFG/ Niterói: EDUFF; 2006, p.358-9.

7. Larkin EA, Carman RJ, Krakauer T, Stiles BG. Staphylococcus aureus: the toxic presence of a pathogen extraordinaire. Curr Med Chem. 2009;30(16):4003-19.

DOI: http://dx.doi.org/10.2174/092986709789352321

8. Brasil. Agência Nacional de Vigilância Sanitária. Resolução RDC n. 275, de 21 de outubro de 2002. Dispõe sobre o Regulamento Técnico de Procedimentos Operacionais Padronizados aplicados aos Estabelecimentos Produtores/Industrializadores de Alimentos e a Lista de verificação das Boas Práticas de Fabricação em Estabelecimentos Produtores/Industrializadores de Alimentos. Diário Oficial [da] República Federativa do Brasil, Poder Executivo, Brasília, DF, 23 out 2003.

9. Brasil. Ministério da Agricultura, Pecuária e Abastecimento. Instrução Normativa n. 62, de 26 de agosto de 2003. Oficializa os Métodos Analíticos Oficiais para Análises Microbiológicas para Controle de Produtos de Origem Animal e Água. Diário Oficial [da] Repúbica Federativa do Brasil, Poder Executivo, Brasília, DF, 18 set 2003. 10. Bauer AW, Kirby EM. Antibiotic susceptibility testing by standardized single disk method. Am J Clin Pathol. 1966;4(45):493-6.

11. Clinical and Laboratory Standards Institute (NCCLS). Performance standards for antimicrobial 
disk susceptibility tests. Acesso: 22 jan 2012. Disponivel em: http://www.clsi.org/

12. Matheus DP, Rudge AC, Gomes SMM. Ocorrência de Salmonella spp em carne de frango comercializada no município de Bauru, SP, Brasil. Rev Inst Adolfo Lutz. 2003;62(2):111-5.

13. Penteado DR, Esmerino LA. Avaliação da qualidade microbiológica da carne de frango comercializada no município de Ponta GrossaParaná. UEPG Biol Health Sci. 2011;1(17):37-45.

14. Kimura AC, Reddy V, Marcus R, Cieslak PR, Boetani JCM, Kassenborr HDS et al. Emerging Infections Program FoodNet Working Group. Chicken consumption is a newly identified risk factor for sporadic Salmonella enteric serotype enteriditis infections in the United States: a casecontrol study in FoodNet sites. Clin Infect Diseas. 2004;3(38):244-52.

DOI:

\section{https://doi.org/10.1086/381576}

15. Brasil. Agência Nacional de Vigilância Sanitária. Resolução RDC n. 13, de 02 de janeiro de 2001(b). Aprova o Regulamento Técnico para Instruções de Uso, Preparo e Conservação na Rotulagem de Carne de Aves e Seus Miúdos Crus, Resfriados ou Congelados. Diário Oficial [da] República Federativa do Brasil, Poder Executivo, Brasília, DF, 2 jan 2001.

16. Freitas MFL, Mota RA, Vilela SMO, Sena MJ, Bezerra R. Cepas de Staphylococcus spp. isoladas de carcaças de frango comercializadas na cidade do Recife-PE, Brasil. Ciên Animal Bras. 2001;2(2):139-45.

17. Olimpo FC, Pereira BM, Oliveira VM. Avaliação da qualidade das carcaças de frango comercializadas no município de Seropédica-RJ. Rev Higiene Alimentar. 2001;80/81(15):142.

18. Brasil. Agência Nacional de Vigilância Sanitária. Resolução RDC n. 12, de 02 de janeiro de 2001(a). Aprova o Regulamento Técnico sobre padrões microbiológicos para alimentos. Diário Oficial [da] República Federativa do Brasil, Poder Executivo, Brasília, DF, 10 jan. 2001.

19. Jay JM. Microbiologia de Alimentos. 6.ed. Porto Alegre: Artmed; 2005. p.711.

20. Chesca AC, Peixoto CP, Costa DG, Nascimento HN, Pinto IRA, Guimarães JLP et al. Levantamento das temperaturas de armazenamento de carnes, em açougues e supermercados de Uberaba, MG. Rev Higiene Alimentar. 2001;84(15):51-5.

21. Souza EL, Silva CA. Qualidade sanitária de equipamentos, superfícies, água e mãos de manipuladores de alguns estabelecimentos que comercializam alimentos na cidade de João Pessoa, PB. Rev Higiene Alimentar. 2004;116/117(18):98-102.
22. Leite LHM, Waissmann W. Surtos de toxinfecções alimentares de origem domiciliar no Brasil, de 2000-2002. Rev Higiene Alimentar. 2006;147(20):56-9.

23. Decara L, Sandoval G, Funes C. Calidad de la carne bovina y bienestar animal en el sur de la província de Córdoba. Redvet. Rev Electr Veter. 2007;12B(8):1695-1704.

24. Xavier CAC, Oporto CF de O, Silva MP, Silveira IA, Abrantes MR. Prevalência de Staphylococcus aureus em manipuladores de alimentos das creches municipais da cidade do Natal/RN. Rev Bras Anál Clín. 2007;3(39):165-8.

25. Yen JR, Brown RB, Dick RL, Acton JC. Oxygen transmission rate of packaging films and light exposure effects on the colour stability of vaccumpackaged dry salami. J Food Sci. 1988;(53):104346. DOI: https://doi.org/10.1111/i.13652621.1988.tb13525.x

26. Brasil. Centro de Vigilância Sanitária da Secretaria de Saúde do Estado de São Paulo. Portaria n. 06, de 10 de março de 1999. Dispõe sobre o regulamento técnico, sobre os parâmetros e critérios para o controle higiênicosanitário em estabelecimento de alimentos. Diário Oficial [do] Estado de São Paulo, 1999.

27. Porte A, Leite MA, Tong P. Monitoramento de carnes e derivados refrigerados expostos à venda em supermercados sulfluminenses. Saúde Rev. 2003;9(5):39-46.

28. Forrest JC, Aberle ED, Hedrick HB, Judge MD, Merkel RA. Fundamentos de ciência de la carne. Zaragoza: Acribia; 1979. p.363.

29. Bergmann GP, Ritter R. Eficácia do sistema de pré-resfriamento de frangos em tanques sobre a redução da contaminação bacteriana de carcaças. Rev Higiene Alimentar. 2003;108(17):97-103.

30. Ogata K, Narimatsu H, Suzuki M. Higuchi W, Yamamoto T, Taniguchi $\mathrm{H}$. Commercially distributed meat as a potential vehicle for community-acquired methicillin-resistant Staphylococcus aureus. Appl Environ Microbiol. 2012;78(8):2797-802. DOI:

https://doi.org/10.1128/AEM.07470-11

Recebido para publicação em 28/08/2015

Revisado em 24/05/2017

Aceito em 30/05/2017 